\title{
A Study of Dairy Heifer Rearing Practices from Birth to Weaning and Their Associated Costs on UK Dairy Farms
}

\author{
Alana C. Boulton, Jonathan Rushton, D. Claire Wathes \\ Department of Production and Population Health, Royal Veterinary College, North Mymms, UK \\ Email: dcwathes@rvc.ac.uk
}

Received 2 March 2015; accepted 8 April 2015; published 10 April 2015

Copyright (C) 2015 by authors and Scientific Research Publishing Inc. This work is licensed under the Creative Commons Attribution International License (CC BY). http://creativecommons.org/licenses/by/4.0/ cC) (i) Open Access

\begin{abstract}
There are many inputs into the dairy replacement herd which impact not only on the cost of rearing heifers from birth to first calving, but also on their future longevity and production potential. This study determined the current cost of rearing dairy heifers in the UK through the calculation and analysis of individual costs on a subset of $102 \mathrm{UK}$ dairy farms. Each farm was visited and an extensive heifer rearing questionnaire was completed. Current heifer rearing practices were recorded to provide insight into critical management decisions. A cost analysis workbook was developed to calculate the costs of inputs in the pre-weaning period for labour, calving, feed, housing, health treatments and vaccinations, waste storage, machinery and equipment, and utilities. The average age at weaning was $62 \mathrm{~d}$. The mean cost of rearing from birth to weaning was $£ 195.19$ per heifer with a mean daily cost of $€ 3.14$ (excluding the opportunity cost of the calf). This ranged from $£ 1.68$ to $£ 6.11$ among farms, reflecting major differences in management strategies and efficiency. The highest contribution to total costs came from feed (colostrum, milk, starter and forage) at $48.5 \%$ with milk feeding making up the greatest proportion of this at $37.3 \%$. The next major expenses were bedding and labour, contributing $12.3 \%$ and $11.2 \%$ respectively. Unsurprisingly, delaying age at weaning increased total cost by $€ 3.53$ per day. Total costs were on average $45 \%$ higher on organic farms than conventional due to higher feed costs and later weaning. Calving pattern also had a strong association with the total cost being lowest with spring calving, intermediate with autumn calving and highest in multi block and all year round calving herds.
\end{abstract}

\section{Keywords}

Weaning, Heifer, Cost Analysis, Economics

How to cite this paper: Boulton, A.C., Rushton, J. and Wathes, D.C. (2015) A Study of Dairy Heifer Rearing Practices from Birth to Weaning and Their Associated Costs on UK Dairy Farms. Open Journal of Animal Sciences, 5, 185-197. 


\section{Introduction}

Dairy heifer wastage is an area of concern on UK dairy farms. A study by Brickell et al. [1] determined that 7.9\% of calves in the UK were born dead or died within the first 24 hours of life with a further $3.4 \%$ of heifer calves dying within the first 28 days of life. Calf and heifer mortality has substantial economic cost not only in terms of the value of the animals, but also in terms of the loss of genetic gain which is cumulative over successive generations [2] and the opportunity cost of resource use up to the point of death. Replacement heifers represent the future of the farm, and the management of the rearing herd is an important factor in the sustainability of not only the farm but also the dairy industry as a whole. Management decisions on planes of nutrition, housing, disease control and breeding all influence growth and development [3] [4]. This, in turn, will affect the age at conception and the age at first calving (AFC), which can have long term economic consequences [5].

In dairy production systems, rearing heifers accounts for approximately $20 \%$ of the costs and is the second largest annual expense after feed for the milking herd [4]. The rearing process is subject to high initial costs with revenue only beginning when the animal starts milk production [6]. The care of dairy youngstock during the initial period of development is crucial to ensure their survival in the milking herd, future milk production and their prospective earnings [7]. During the pre-weaning period, the calf undergoes fundamental physiological changes and is also subjected to additional stresses during this time such as regrouping and dehorning which can have negative impacts on growth and development. With the increase of herd size in the UK, the number of calves that farmers are rearing has also led to greater pressures on housing and labour.

During the pre-weaning period, the main feed cost is clearly milk, provided either as milk replacer or whole milk from the dairy. The decision to feed a restricted or enhanced feeding programme not only has financial implications, but also affects feed efficiency and growth [8]. Studies examining intensified feeding programmes have found that heifers attain puberty, conceive and calve earlier, and produce more milk during their first lactation than heifers fed conventional feeding programmes [9]. Heinrichs and Heinrichs [10] also showed that a $1 \mathrm{~kg}$ increase in dry matter intake (DMI) at weaning produced a $286.7 \mathrm{~kg}$ increase in first lactation milk yield and that the age at which calves began to consume $>900 \mathrm{~g}$ /day was associated with an increased lifetime production of milk and milk constituents.

From birth onwards calves are exposed to pathogens responsible for major calfhood disease symptoms such as diarrhoea and pneumonia [11] [12]. The cost of disease is not restricted to the cost of veterinary medicines or prophylactic treatments, as it also has long term economic effects due to reduced average daily gain (ADG), increased culling and later AFC resulting in an increased non-productive period [4] [10] [13]. A study examining early calfhood health status on AFC and longevity in Canadian Holstein dairy herds discovered that heifers treated for pneumonia were 2.5 times more likely to die after 90 days than untreated heifers and that those treated for scours were 2.5 times more likely to be sold than other calves [14].

The direct and indirect cost of heifer rearing can be difficult to recognize and quantify due to the limited time the farmer has to record the quantities and cost of all the inputs to the heifer rearing system and the time lag between those inputs and the revenue from milk production. The aim of this study was to investigate current rearing practices on a range of dairy farming systems in the UK and to generate accurate data on the cost of heifer rearing in these systems, taking into account the cost of heifer mortality.

\section{Materials and Methods}

\subsection{Farm Selection, Questionnaire and Data Collection}

Farmers were recruited via industry extension services, farm consultancy groups, social media platforms and private veterinary groups. A total of 102 dairy farms in England, Scotland and Wales were included that could provide all the information on their youngstock rearing from birth to first calving. These were visited from March to August 2013. Although the selection of farms was not random, the geographical distribution, breed, size and enterprise type reflected the characteristics of dairy farms in the UK.

A face-to-face interview with questionnaire was completed by a single researcher during a one-day farm visit. The questionnaire was based on a Canadian study [15], which identified the most important factors affecting successful heifer rearing. It was approved by the Royal Veterinary College Ethics and Welfare Committee (number 2013 1199). The questionnaire took between 40 and 120 minutes to complete depending on the ease of access to certain data by the farmer. The whole survey covered the period from birth to first calving and included 46 closed 
and 78 open questions recording details of on-farm calf and heifer management, focusing on the areas of calving, neonatal care, weaning, feeding, housing, health and disease. Input costs were obtained for the items covered. It also recorded farm factors including whether the farm was organic or conventional, ownership status, calving pattern, predominant breed, whether the farm was dairy only or a mixed enterprise, bovine Tuberculosis (bTB) status, total number of milking cows, culling rate, calving rate, stillbirth rate, the average first 305-day lactation yield (litres) and average total herd 305-day yield (litres). UK legislation requires regular testing of all cattle for the presence of bTB and places strict limitations on any animal movement on or off premises on which an animal has tested positive (The Tuberculosis (England) Order 2014

http://www.legislation.gov.uk/uksi/2014/2383/article/8/made). This paper covers the period from birth to weaning, which was addressed in 28 closed and 32 open survey questions.

\subsection{Calculation and Analysis of Input Costs}

A cost analysis workbook was developed in Microsoft Excel 2010 with a separate worksheet for each individual input. All input cost estimates on a per heifer basis were collated to provide a total cost of rearing from birth to weaning. The cost per day was based on the average age of weaning on individual farms.

The total number of people involved in the care and management of youngstock and the number of hours per day spent on farm duties directly associated with youngstock rearing were recorded. An hourly wage rate of $£ 9.99$ (including National Insurance Employer Contribution and Employer's Liability Insurance) was used to calculate the cost of labour, based on an average of minimum wages detailed in the Agricultural Wages (England and Wales) Order [16] for labour grades that possess the appropriate vocational qualifications to care for and manage youngstock.

The costs of calving included bedding, disinfecting and cleaning the calving shed together with the cost of disposal of stillborn calves. This was set at $£ 30.00$ per dead heifer calf unless specified otherwise by the farm. The cost of colostrum was based on the number of days that colostrum and transition milk were fed, the number of feeds per day, the quantity fed and the cost of production. The product used to treat the navel following birth and the age and method used to dehorn calves were recorded. The cost of dehorning included labour and the anaesthetic and/or anti-inflammatories administered pre- and post-procedure. The cost of the drugs was based on the recommended dosage of the product used.

The type of milk or milk replacer, volume per feed (L), density of the feed $(\mathrm{g} / \mathrm{L})$ and number of feeds per day were recorded. For automatic milk feeders the amounts were calculated in $0.5 \mathrm{~L}$ increments taking into account the number of programmed feeds per day. The cost of whole milk was calculated using the most recent average farmgate price. The cost of waste milk and fermented milk was calculated using the current cost of production and milk replacer was costed using the most recent purchase price.

The age that dry feed was introduced and the amount consumed by weaning were recorded. These figures were used to estimate the total quantity of calf starter per heifer as no farm measured daily consumption. A model was developed in Microsoft Excel 2010 using Equation (1):

$$
y=0.0007 x^{2}-0.001 x-0.0063
$$

where $y=$ starter dry matter intake (kg/d); $x=$ age (days) [17] [18].

The cost of starter feed was based on the price paid by the farmer to the feed merchant: if produced on farm, then quantities and price per tonne of each component of the feed was recorded and an overall price per tonne was calculated. The amount of forage consumed was estimated using results from a study by Jasper and Weary [18]. The cost of forage was based on the price per tonne given by the farmer. If this was not known then ex-farm prices for the relevant period were obtained from the British Hay and Straw Merchants Association (Horningsea, Cambridge, UK).

The survey recorded the age in days at which calves were given free access to water. It was assumed that all water supplied to youngstock was metered and so it was charged at the rate appropriate to the regional location of the farm and its' water supplier. A model was developed in Microsoft Excel 2010 based on the recommended daily liveweight gains for small, medium and large size dairy breeds in the UK [19]. As the animal aged in daily increments, the liveweight gain was added to the current bodyweight. This was then multiplied by the factor of 1 $\mathrm{kg}=0.1001 \mathrm{~L}$ to calculate the expected water intake at that body weight. These calculations did not account for increased or decreased water intake that would be expected with extremes of temperature. 
For electricity, an estimated consumption of $100 \mathrm{kWh}$ per year per heifer was used [20]. The average standing charge and average unit price of the main energy providers in the UK were $103.7 \mathrm{p} / \mathrm{d}$ and $11 \mathrm{p} / \mathrm{kWh}$, respectively. The proportion of the daily standing charge apportioned to each heifer was dependent upon the size of the herd.The cost of slurry storage during the pre-weaning period was based on a 7.0 litres/day production up to 91 days of age and then 20.0 litres/day aged $>91$ days [21]. The cost per cubic meter of storage was $£ 22$.

The questionnaire recorded the age that calves entered their new accommodation following calving, the type of housing, whether the calf was individually or group housed and the number of calves per housing unit, size of the housing unit and the number of days in that housing unit. Some calves were moved several times during the weaning period and each of these variables were recorded for every housing unit. The type of bedding used along with the price per tonne for the bedding was recorded as were the number of times that fresh bedding was added to the calf pen and how often the pen was mucked out and rebedded. Finally, it was noted whether disinfection took place during rebedding.

The cost of calf disease treatment was based on the product used for treatment, the quantity of medication required and the duration of treatment. The cost of vaccination during the pre-weaning period was based on the cost of the vaccine being administered, the recommended dosage and the number of doses. Boosters given after weaning were not included. The labour cost of vaccination was included in the time allocated to duties directly associated with youngstock.

The cost of building depreciation was based on a useful lifetime of 20 years for steel or wood framed portal buildings and stone buildings and 10 years for calf hutches. The cost apportioned was based on the number of heifers housed in the accommodation. It was assumed that metal and moulded plastic milk and dry feeders had 10 years of useful life with only the teats being replaced annually at an average cost of $£ 30.00$ for a pack of 10 . The depreciation rate of automatic milk feeders and pasteurization machines was based on those of milking machines [22]. This was $2 \%$ for an annual usage of $50 \mathrm{~h}, 4 \%$ for $100 \mathrm{~h}, 5.5 \%$ for $150 \mathrm{~h}$ and $7 \%$ for $200 \mathrm{~h}$. Each additional $100 \mathrm{~h}$ resulted in $+3.0 \%$ of depreciation. Smaller less expensive items such as plastic buckets and oesophageal tube feeders had no salvage value at the end of their useful life. The cost of ear tags was included but not the cost of registering calves with the breed society.

\subsection{Statistical Analysis}

The cost data collated in Microsoft Office Excel 2010 were imported into STATA v12.1 (StataCorp, College Station, Texas, USA) for analysis. Simple linear regression was used to test for associations between each of the farm factors and the cost of rearing. The Shapiro-Wilk test was used to test for normality and the Breusch-Pagan/ Cook Weisberg test for heteroskedasticity. Variables were also compared graphically for normality and linearity. If the plot of residuals against each of the continuous predictor variables failed, the continuous predictor variables were categorized. Analysis of variance (ANOVA) was used to test for differences between the means of categorical variables. Variables with $p$-values $<0.2$ in univariable analyses were included in a multivariable analysis. A forward stepwise selection procedure was undertaken to determine the model starting with the variable with the highest F statistic and lowest $p$-value from the univariable analysis. The results of the ANOVA were used to determine the fit of the model. Tests for interactions were also conducted.

\section{Results}

The contribution of each of the input costs to the total cost is summarized in Table 1 and Figure 1.

\subsection{Labour}

The cost of labour during the pre-weaned period varied considerably between farms $(\mathrm{n}=102)$, influenced mainly by the time allocated per day and the age at weaning. The mean time spent was $2.1 \pm 1.66 \mathrm{~min} / \mathrm{heifer} / \mathrm{d}$ (range 0.45 to 12.0 , median 1.6). The mean cost of labour per heifer per day was $£ 0.36 \pm 0.28$ (range $£ 0.07$ to $£ 2.00$, median £0.26). The average age at weaning was $62 \pm 13.3 \mathrm{~d}$ (range 42 to $112 \mathrm{~d}$, median $56 \mathrm{~d}$ ). The overall labour costs for the pre-weaning period were therefore $£ 22.32 \pm 16.42$ per heifer (range $£ 3.13$ to $£ 139.86$, median $=£ 18.84)$. This median cost was fairly consistent for heifers weaned between 6 and 10 weeks of age but increased for heifers weaned at 11 weeks or older. 
Table 1. Summary data of the contribution of each of the costs assessed to the total cost per farm from birth to weaning ${ }^{\#}$.

\begin{tabular}{|c|c|c|c|c|}
\hline \multirow{2}{*}{ Input } & \multicolumn{4}{|c|}{$\%$ contribution to total cost of weaning } \\
\hline & $\mathrm{n}$ & Mean & Range & Median \\
\hline Labour & 102 & $11.2 \pm 7.2$ & $2.7-48.9$ & 9.5 \\
\hline Calving management & 102 & $4.4 \pm 2.9$ & $0.4-13.5$ & 3.6 \\
\hline Colostrum & 102 & $2.1 \pm 1.5$ & $0.4-6.6$ & 1.7 \\
\hline Navel and dehorning treatments & 102 & $0.5 \pm 1.2$ & $0-9.5$ & 0.2 \\
\hline Eartags & 102 & $1.1 \pm 0.4$ & $0.4-2.1$ & 1.1 \\
\hline Milk feeding & 102 & $37.3 \pm 9.4$ & $18.0-66.8$ & 36.5 \\
\hline Starter feed & 102 & $9.0 \pm 4.9$ & $0.7-30.6$ & 7.9 \\
\hline Forage & 77 & $0.1 \pm 0.1$ & $0-0.3$ & 0.1 \\
\hline Drinking water & 100 & $0.3 \pm 0.1$ & $0-0.6$ & 0.3 \\
\hline Electricity & 102 & $1.1 \pm 0.3$ & $0.5-2.8$ & 1.1 \\
\hline Bedding & 101 & $12.3 \pm 8.4$ & $0-33.0$ & 11.3 \\
\hline Disinfection of housing area & 78 & $1.3 \pm 1.3$ & $0-6.8$ & 1.0 \\
\hline Disease treatment & 99 & $5.7 \pm 3.8$ & $0-16.6$ & 5.1 \\
\hline Vaccination & 30 & $3.9 \pm 7.0$ & $0-27.4$ & 0 \\
\hline Slurry & 101 & $5.4 \pm 3.0$ & $0-15.4$ & 4.7 \\
\hline Building depreciation & 101 & $2.3 \pm 1.0$ & $0-5.5$ & 2.2 \\
\hline Machinery and equipment depreciation & 102 & $2.0 \pm 0.9$ & $0.6-6.3$ & 1.8 \\
\hline
\end{tabular}

\#There were 102 farms in the study but not all farms used all the potential inputs which were assessed.

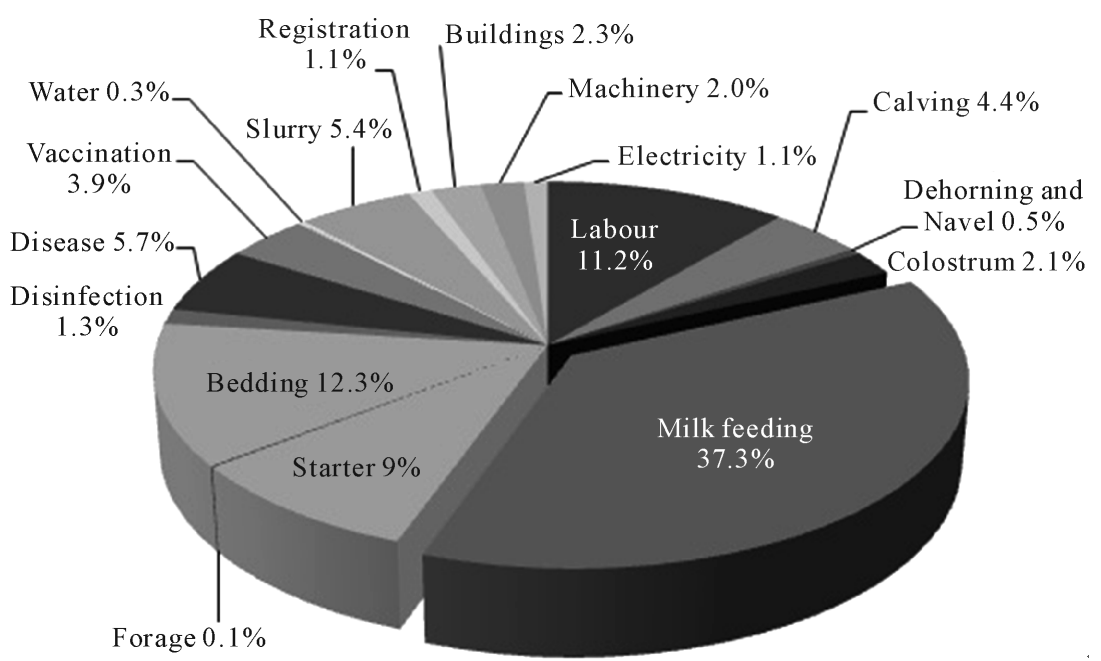

Figure 1. Contribution of input costs to total cost of rearing from birth to weaning.

\subsection{Calving Management}

Approximately $74 \%$ of farms $(n=75)$ added fresh bedding daily to the calving pen with four weeks being the most frequent time interval for mucking out and rebedding $(\mathrm{n}=38)$. The mean cost of bedding material in the calving pen was $£ 0.88 \pm 0.67$ per heifer (range $£ 0.09$ to $£ 5.91, \mathrm{n}=98$ ). Only 54 farms $(52.9 \%)$ undertook some form of disinfection or deep cleaning of the calving area with the cost per heifer ranging from $£ 0.01$ to $£ 10.60$. The mean disposal costs of stillborn heifer calves applied to the remaining liveborn heifers was $£ 7.10 \pm 5.07$ per 
heifer (range $£ 0.00$ to $£ 25.56$, median $£ 6.33$ ). The highest disposal costs were in small to medium sized herds (range 50 to 155 milking cows, $\mathrm{n}=35$ ) with an average stillbirth rate of $5.5 \% \pm 3.2 \%$ (range $0 \%$ to $13.9 \%$, me$\operatorname{dian} 4.6 \%)$.

\subsection{Colostrum Management and Separation from the Dam}

The most commonly used method for feeding the first meal of colostrum was via a teat bottle ( $\mathrm{n}=49$ farms), with $83 \%$ of farmers $(n=85)$ employing an oesophageal tube if the calf failed to consume sufficient colostrum during the first feed. Only $32 \%$ of farms $(n=33)$ ensured that both the first and second feed were from the first milking, confirming two feeds of true colostrum. More than half of the farms surveyed (57\%) did not check the quality of the colostrum before use, with only $42 \%$ taking a management decision to either increase volume, use artificial colostrum or use another dam's milk (frozen or fresh) if the quality was not good or excellent. Calves were fed colostrum for $3.1 \pm 1.8$ days (range 0.5 to 10 days). The mean cost per $\mathrm{L}$ of colostrum, based on the cost of production on the farm, was $£ 0.26 \pm 0.05$ (range $£ 0.13$ to $£ 0.33$ ).

\subsection{Navel Treatment, Dehorning and Eartags}

The routine treatment of the navel following birth was practised by $82 \%$ of surveyed farms $(\mathrm{n}=84)$. The most frequently used product was iodine $(n=68)$ with the average cost of disinfection being $£ 0.16 \pm 0.03$ per heifer (range $£ 0.11$ to $£ 0.37, n=84)$. Approximately $90 \%$ of farms $(n=92)$ dehorned their heifers before weaning with more than half (57\%) doing so between 3 and 6 weeks of age. Gas and electrical hot irons accounted for $90 \%$ of the farms' choice of dehorning method. The use of anaesthetic during dehorning was practiced by $85 \%$ of farms $(n=87)$ with the most commonly used being Lignocaine/Lidocaine (Norbrook Laboratories Ltd., County Down, Northern Ireland). Nine of the study farms used a second veterinary treatment during dehorning: six used the anti-inflammatory Metacam (Boehringer Ingelheim, Vetmedica GmbH, Germany), two used Terramycin (Zoetis UK Limited, London, UK) and one farm used a homeopathic remedy 20 min prior to dehorning. Four farms used veterinarians to perform dehorning whilst on the remainder of farms the task was undertaken by farm workers. The cost of registration for calves was set at $£ 2.00$ for eartags.

\subsection{Milk Feeding}

The most common type of milk fed to heifer calves was reconstituted milk replacer (55\%) followed by whole milk (18\%). Milk was most commonly fed warm (95\%) with the milk feeding systems most frequently employed being a bucket (36\%) and multi teat feeder (24\%). Only 20\% of farms surveyed used automatic milk feeders. The average volume of milk fed to a heifer calf per day was $4.58 \pm 1.33 \mathrm{~L}$ (range 2.1512 .59 , median $=$ 4.39). This included one farm which fed milk on an ad libitum basis. The average cost of milk fed was $0.26 \pm$ $0.10 £ / \mathrm{L}$ (range 0.13 to 0.80 , median 0.24 ). In 25 farms the cost per $\mathrm{L}$ was $<£ 0.20$, in 62 farms it was between $£ 0.21$ and $£ 0.30$ and in 15 farms it was $>£ 0.30$.

Weaning occurred at a mean age of $62 \pm 13.3$ days (range 42 to 112 , median $=56$ ). The method employed most frequently to wean heifer calves was reducing the volume of milk fed per day (56\%) followed by the abrupt cessation of milk feeding (25\%). Other methods included reducing the number of milk feeds per day (13\%), diluting milk with water $(6 \%)$ and reducing the density of milk powder $(2 \%)$. The most common criteria for deciding to wean calves off milk were age (53\%), size (19\%) and feed intake (17\%).

\subsection{Dry Feed}

Dry feed was regularly introduced to heifer calves at $<1$ week of age $(n=82)$ with the most common being calf starter pellets $(60 \%)$. The estimated mean amount of starter consumed was $0.8 \pm 0.3 \mathrm{~kg} / \mathrm{heifer} / \mathrm{d}$ (range 0.3 to 2.3). The associated cost of the starter was $0.27 \pm 0.17 £ /$ heifer/d (range 0.03 to 0.95 , median 0.22 ). Forage was fed to heifer calves on 77 farms, most frequently wheat straw (46\%) followed by hay and barley straw (11\%). The mean cost of forage was $0.25 \pm 0.14 £ /$ heifer/d (range 0.10 to $0.68, \mathrm{n}=77$ ).

\subsection{Drinking Water and Electricity}

Approximately $50 \%$ of farms introduced water within the first $2 \mathrm{~d}$ of life with $78 \%$ in the first 7 d. Average daily 
water consumption per heifer was estimated at $6.1 \pm 0.7 \mathrm{~L}$ (range 4.1 to 8.3 ). Two farms did not provide access to water until after weaning. The cost per cubic meter of water varied between regions and water suppliers. The mean cost for water consumption was $0.008 \pm 0.003 £ /$ heifer/d (range 0.00 to $£ 0.016$ ). Water used for cleaning was included in the cost of disinfection. The mean cost of electricity per heifer was $£ 2.09 \pm 0.59$ (range $£ 1.38$ to $£ 5.27$, median £1.89).

\subsection{Housing, Bedding and Slurry}

One of the 102 farms reared its pre-weaned calves on grass. Most others housed their heifer calves individually $(65 \%)$ for their first accommodation, if not for the duration of the pre-weaned period. The average area allotted per heifer, including those group housed, was $2.2 \pm 2.0 \mathrm{~m}^{2}$ (range 0.8 to 14.5 ). Approximately half (51\%) of the farms surveyed added fresh bedding daily to the calf pens, with $26 \%$ adding bedding every alternate day. Pens were mucked out and rebedded normally every 4 weeks (36\%): however $9 \%$ of farms only mucked out after all heifers had been weaned or turned out after a period of time housed ( $>12$ weeks). The mean cost of bedding was $0.41 \pm 0.34 £ /$ heifer/d (range 0.01 to 1.43 , median 0.32). Disinfection or deep cleaning of calf housing occurred routinely on $76 \%$ of farms with lime being the most frequently used product. The mean cost of disinfection was $0.07 \pm 0.15 £ /$ heifer/d (range 0.01 to $1.34, \mathrm{n}=78$, median 0.03 ). The mean cost of slurry and spreading soiled bedding was $£ 9.66 \pm 2.59$ (range $£ 6.47$ to $£ 23.25$, median $£ 8.62, \mathrm{n}=101$ ).

\subsection{Disease and Health Treatments}

The most commonly treated calfhood health condition was diarrhoea (scours) followed by pneumonia (Table 2). A total of 92 of the farms surveyed treated at least one heifer calf for an episode of scours. The most common (61\%) form of treatment was oral rehydration therapy with an average cost per incidence of scours being $£ 6.37$ \pm 4.95 (range $£ 0.69$ to $£ 19.81, \mathrm{n}=90$, median $£ 5.48$ ). Treatment for respiratory conditions routinely included the use of antibiotics and/or anti-inflammatories. The mean cost per incidence of pneumonia was $£ 4.12 \pm 1.74$ (range $£ 0.54$ to $£ 11.55, \mathrm{n}=88$, median $£ 4.67$ ). The mean cost of treating navel infections and swollen joints being $£ 1.21 \pm 1.33$ (range $£ 0.32$ to $£ 6.13$ ) and $£ 1.25 \pm £ 1.25$ (range $£ 0.54$ to £4.67) respectively, with both conditions having a median cost of $£ 0.54$.

\subsection{Vaccinations}

A total of 30 farms administered at least one type of vaccination, with 10 farms administering multiple vaccinations during the pre-weaning period. The average cost of vaccination per heifer was $£ 28.40 \pm 11.71$ (range $£ 2.88$ to $£ 52.92, \mathrm{n}=30$, median $£ 31.72$ ). The most common vaccines used were against respiratory disease ( 31 farms), followed by Coccidiosis and Leptospira spp. (4 farms each), Cryptosporidium parvum ( 2 farms) and Clostridium chauvoei, Pasteurella trehalosi and Salmonella spp. (1 farm each).

\subsection{Building, Machinery and Equipment Depreciation}

The mean cost of building depreciation for the pre-weaning period was $£ 4.32 \pm 1.92$ per heifer (range $£ 0.40$ to $£ 10.91$, median $=£ 4.02, \mathrm{n}=101)$ with values of $0.07 \pm 0.03 £ /$ heifer $/ \mathrm{d}$ (range 0.004 to $0.14, \mathrm{n}=101)$. The mean cost of machinery and equipment depreciation was $£ 3.57 \pm 1.68$ (range $£ 1.73$ to $£ 16.53$, median $=£ 3.35$ ).

Table 2. Proportion of heifers per farm treated for a health condition on the 102 farms surveyed ${ }^{\#}$.

\begin{tabular}{cccc}
\hline \multirow{2}{*}{ Health condition } & $\begin{array}{c}\text { Proportion of farms } \\
\text { reporting this condition }\end{array}$ & Mean \pm SD & Proportion of heifers per farm treated \\
\cline { 3 - 4 } Scours & $90 \%$ & $12.6 \% \pm 16.8 \%$ & $100 \%-0 \%$ \\
Pneumonia & $86 \%$ & $11.3 \% \pm 15.8 \%$ & $100 \%-0 \%$ \\
Umbilical infection & $57 \%$ & $1.2 \% \pm 2.3 \%$ & $15.4 \%-0 \%$ \\
Swollen joints & $31 \%$ & $0.40 \% \pm 1.1 \%$ & $10.3 \%-0 \%$ \\
\hline
\end{tabular}

${ }^{\#}$ There were 102 farms in the study but not all farms used all the potential inputs which were assessed. 


\subsection{Total Cost of Rearing from Birth to Weaning}

Adding all these input costs together, the mean total cost of rearing from birth to weaning on the 102 farms surveyed was $£ 195.19 \pm 68.44$ (range $£ 94.64$ to $£ 499.80$, median $£ 188.25$ ). The contributions of the various component costs to this total are summarised in Table 1 and Figure 1. Feed (colostrum, milk, starter and forage) was the main component at $48.5 \%$, with milk accounting for $37.3 \%$ of this. The second and third highest expenses during the pre-weaning period were bedding and labour contributing $12.3 \%$ and $11.2 \%$ of total costs respectively. When the costs were expressed per heifer per day (excluding the initial value of the calf) the mean was $£ 3.14$ \pm 0.85 (range $£ 1.68$ to $£ 6.11$, median $£ 3.03$ ).

The mean cost of rearing calves from birth to weaning was on average $45 \%$ higher on organic farms compared to conventional farms at $£ 271.48 \pm 93.96$ (range $£ 187.84$ to $£ 499.80$, median $£ 260.94, \mathrm{n}=9$ ) and $£ 187.81$ \pm 61.24 (range $£ 94.64$ to $£ 349.68$, median $£ 178.87, \mathrm{n}=93$ ) respectively. The mean total cost of rearing to weaning was lowest in spring calving herds $(£ 123.60 \pm 14.12, n=5)$, intermediate in autumn calving herds ( $£ 173.53 \pm 62.04, \mathrm{n}=14$ ) and highest in multi block and all year round calving herds ( $£ 204.18 \pm 50.85, \mathrm{n}=10$ and $£ 203.02 \pm 70.86, \mathrm{n}=73$ respectively). These figures translated into the following mean cost per day: spring $£ 2.10 \pm 0.37$, autumn $£ 2.73 \pm 0.70$, all year round $£ 3.26 \pm 0.81$ and multi block calving $£ 3.37 \pm 1.02$ (Figure 2).

\subsection{Variables Influencing the Cost of Rearing from Birth to Weaning}

The main variables affecting the total cost of rearing from birth to weaning were age at weaning and type of enterprise (conventional or organic) with a lesser influence of calving pattern (Table 3 and Figure 3). The remaining variables tested (breed, region, herd size, culling rate, calving rate, stillbirth rate, first lactation yield, herd lactation yield and bovine TB status of herd) suggested no association with the cost of rearing in this period. The outcome of the final multivariable model was that age at weaning, enterprise type and calving pattern accounted for $48.7 \%$ of the variability in the cost of rearing from birth to weaning with an $\mathrm{F}(5,96)$ statistic of $18.22(p<0.0001)$. Adjusting for the effect of enterprise type and calving pattern, the mean cost of rearing from birth to weaning increased by $£ 3.53$ per calf for each extra day. The predicted decrease in mean cost of rearing on autumn and spring block calving farms compared to all year round calving farms was $£ 29.89$ and $£ 70.93$

Table 3. The effect of different exposure variables on the total cost of rearing from birth to weaning assessed using one way ANOVA.

\begin{tabular}{ccccc}
\hline Variable $^{\#}$ & df & F & Prob $>F$ & ${\text { Adj } R^{2}}^{2}$ \\
\hline Age at weaning & 1,100 & 69.84 & $<0.0001$ & 0.4053 \\
Enterprise type & 1,100 & 13.82 & 0.0003 & 0.1126 \\
Calving pattern & 3,98 & 2.81 & 0.0434 & 0.0510 \\
Breed & 5,96 & 1.37 & 0.2440 & -0.0090 \\
Region & 9,92 & 0.67 & 0.7336 & -0.0303 \\
Herd size & 4,97 & 1.26 & 0.2891 & 0.0104 \\
Culling rate \% & 5,96 & 1.95 & 0.0925 & 0.0451 \\
Calving rate \% & 5,96 & 0.56 & 0.7335 & -0.0225 \\
Stillbirth rate \% & 4,97 & 0.16 & 0.9597 & -0.0346 \\
First lactation yield & 5,95 & 0.43 & 0.8299 & -0.0296 \\
Herd lactation yield & 5,95 & 0.52 & 0.7601 & -0.0243 \\
bTB status & 1,100 & 1.72 & 0.1926 & 0.0071 \\
\hline
\end{tabular}

\#Age at weaning, age that milk feeding ceased; enterprise type, classification of farms on their organic status; calving pattern, season(s) when the majority of the herd calved; breed, predominant breed in the herd; herd size, number of cows in the milking herd including dry cows; culling rate, \% cows in the herd culled in the last 12 months; calving rate, \% cows in the herd calved in the last 12 months; stillbirth rate, \% calves born dead from the number of cows that calved in the last 12 months; first lactation and herd lactation yield, respective average yields (kg) from the most recent 305-day lactation records; bTB status, whether the farm was currently under movement restrictions. 


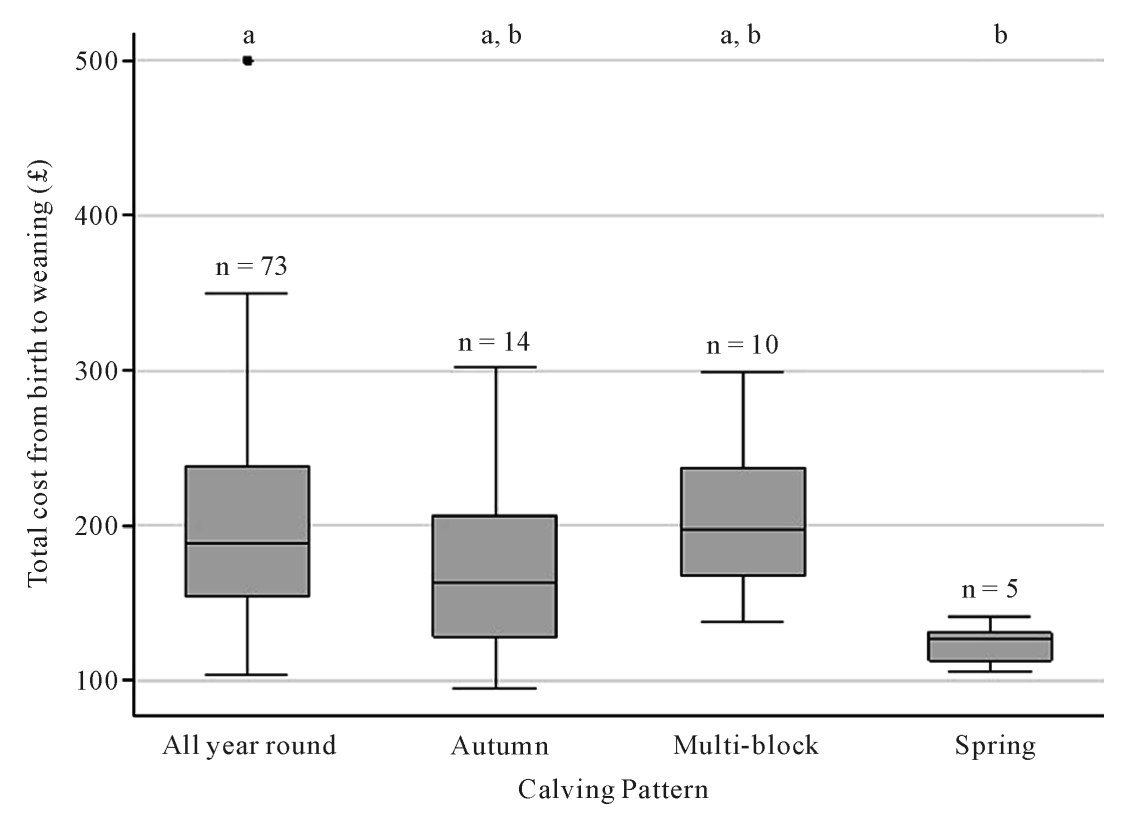

Figure 2. Box and whisker plots showing the total cost of weaning for the four different calving patterns: $\mathrm{a}>\mathrm{b}, p<0.05$.

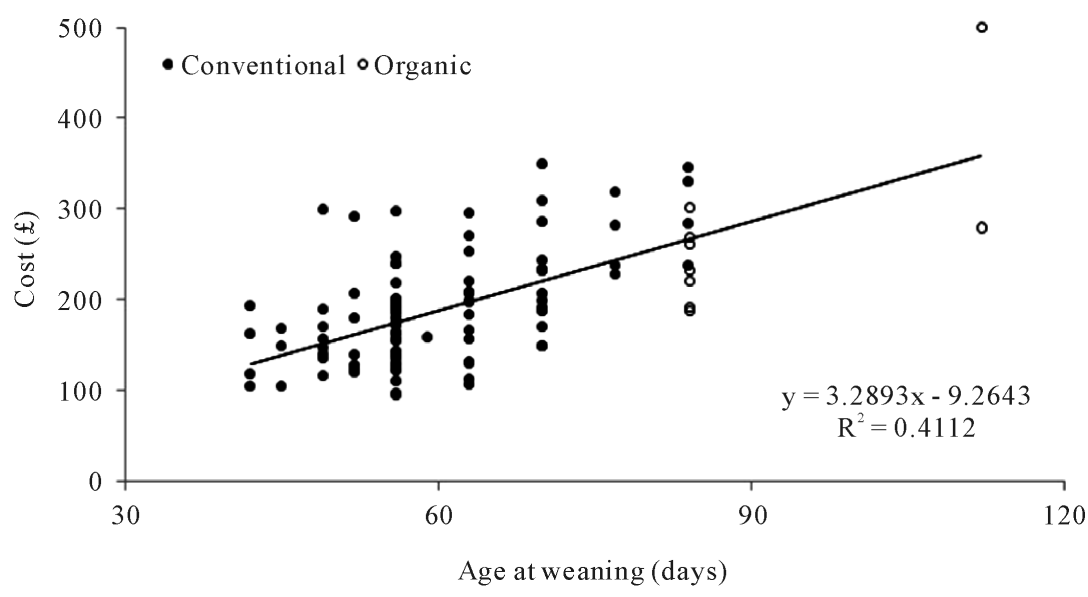

Figure 3. Regression analysis between age at weaning and cost of rearing from birth to weaning. Each symbol represents one farm, $\mathrm{n}=102$.

respectively after adjusting for age at weaning and enterprise type. The effect of enterprise type was no longer significant after adjusting for age at weaning and calving pattern $(p=0.454)$ (Table 4).

\section{Discussion}

Our study has provided a comprehensive analysis of all the costs involved in rearing dairy heifer calves from birth to weaning. Face-to-face interviews were conducted with detailed information obtained on the physical quantities of inputs used and outputs produced on each farm. Whilst economic estimation of farm enterprise input use and costs is a less expensive alternative than interviews, the context in which decisions are being made and the biological and sociological explanations behind the output are lost. Examining the literature for earlier studies on the economics of heifer rearing produced few results, with most information being in the grey literature produced by university and agricultural consultancy business extension services, most of which originated outside the UK. Many such extension service publications present a single figure either for different ages at first calving or for different calving systems such as autumn or spring calving [23] [24]. Key costs are often omitted 
Table 4. Results of multivariable linear regression analysis of cost of rearing pre-weaning and age at weaning, enterprise type and calving pattern.

\begin{tabular}{|c|c|c|c|c|c|c|c|c|}
\hline Variable & & $\mathrm{n}$ & Coefficient & Std. error & $\mathrm{t}$ & $p>|t|$ & \multicolumn{2}{|c|}{$95 \% \mathrm{CI}$} \\
\hline Age at weaning & & 102 & 3.53 & 0.51 & 6.94 & $<0.0001$ & 2.52 & 4.54 \\
\hline \multirow{2}{*}{ Enterprise type } & Baseline & 93 & \multicolumn{6}{|c|}{ Conventional } \\
\hline & Organic & 9 & -18.64 & 24.79 & -0.75 & 0.454 & -67.85 & 30.57 \\
\hline \multirow{4}{*}{ Calving pattern } & Baseline & 73 & \multicolumn{6}{|c|}{ All year round } \\
\hline & Autumn & 14 & -29.89 & 15.60 & -1.92 & 0.058 & -60.85 & 1.07 \\
\hline & Multi block & 10 & 1.63 & 16.99 & 0.10 & 0.924 & -32.09 & 35.36 \\
\hline & Spring & 5 & -70.93 & 23.27 & -3.05 & 0.003 & -117.13 & -24.74 \\
\hline
\end{tabular}

and no ranges of costs for the various inputs are offered. A more comprehensive approach was therefore needed.

We found that while rearing practices have changed on many farms during recent years, practices passed on from previous generations still pervaded many management decisions particularly in regards to feeding.

The mean total cost of rearing dairy heifer calves in the UK from birth to weaning in 2013 was $£ 195.19$ with a wide range from $£ 94.64$ to $£ 499.80$ and a mean daily cost of $£ 3.14$. In this study milk feeding was the single greatest expense, accounting for approximately $40 \%$ of total costs during this period. With the addition of colostrum, starter and forage costs, feed accounted for almost $50 \%$ of total costs. This figure is in agreement with Karzes [25] who found that feed contributed to $51 \%$ of rearing costs and that purchased feed such as milk replacer contributed to $38 \%$ of costs. In a Dutch study [26], dairy herds' feed accounted for $44.5 \%$ of rearing costs up to first calving at 25 months, with no separate figures given for the proportion of costs attributed to milk feed or to the pre-weaning period. This is in comparison with the results of 44 USA farms [27] which found that feed costs accounted for nearly $73 \%$ of the total cost of rearing and $57 \%$ of the total cost from birth to weaning. In this same study feed costs were highly correlated with labour costs during the pre-weaning period. This is to be expected due to the labour intensive nature of milk feeding, particularly in non-automated feed systems. The reason that the proportional cost of feed was higher in the USA study could be due to the fact that capital costs were not included in their analysis.

Bedding costs reflect the frequency that calf accommodation is mucked out and rebedded. Moist bedding increases ammonia levels in calf housing which can increase the risk of respiratory disease and also adds to heat loss [3] [28]. The mean contribution of bedding to weaning costs in this study was $12.3 \%$ (range $0 \%$ to $33.0 \%$ ) compared to Heinrichs et al. [27] who attributed $5.5 \%$ of the cost of weaning to bedding (range $0 \%$ to $16.9 \%$ ). Whilst Heinrichs' study states that bedding costs ranged greatly between farms and that bedding was expensive, the volume of bedding used and the cost per tonne of bedding material was not stated. In the UK the cost of bedding ranged from $£ 12$ to $£ 120$ a tonne, with location of the farm having a large influence on the purchase price or opportunity cost of the bedding material. The volume of bedding was also dependent upon the size of the accommodation per heifer with minimum requirements set down in statutory regulations in the UK.

Labour was the third highest expense during the rearing period accounting for on average $11.2 \%$ of total costs. As stated previously, milk feeding is labour intensive. This included colostrum feeding, which was undertaken either instead of or alongside suckling from the dam. The practice of mucking out and rebedding calf accommodation was also more frequent during the pre-weaning period as was routine disinfection. Labour costs in other studies contributed between $14.1 \%$ and $34.9 \%$ to the total cost from birth to weaning with mean contributions of $26.9 \%$ [27] and $13.8 \%$ [29]. The range in the current study was $2.7 \%$ to $48.9 \%$ of total costs; however $92 \%(94 / 102)$ of farms had labour costs that were less than $20 \%$ of the total cost to weaning.

Health costs in the study only accounted for the cost of veterinary treatment for specific health problems. The hidden costs of disease are due to growth checks as a result of inappetence during the period of illness which can lead to delayed breeding and greater age at first calving [4] [10]. In this study it is likely that the incidence of disease has been underreported on a number of farms as the mean incidence of scours and respiratory infections was $14.0 \%$ and $13.1 \%$ respectively. This compares with a survey of English dairy farms undertaken in 2010 to 2013 where incidence of scours and respiratory disease was recorded at $48 \%$ and $46 \%$ respectively (K. Johnson 
personal communication). The contribution of veterinary medicines to the cost until weaning ranged from $0 \%$ to $16.6 \%$ with a mean of $5.7 \%$. This was higher than another study [27] which reported a mean contribution of "health" costs of $2.9 \%$ (range $0.2 \%$ to $4.8 \%$ ) which included the cost of vaccination and worming treatments along with veterinary medicines.

The study has shown that the cost of rearing per heifer during the pre-weaning period varied over five-fold from $£ 94.64$ to $£ 499.80$. A major determinant of this was the age at weaning. This varied from 42 to 112 days between herds, with each extra day adding $£ 3.53$ to the overall total. This compared to the estimated cost per day post weaning which was only $£ 1.65 \pm 0.40$ (Boulton, Rushton and Wathes, unpublished observations). It is important for farmers to understand their costs of production to improve efficiency as this will influence the viability of their enterprise as a whole. On the other hand, economizing too much during this critical period is likely to be counter-productive in the long term, with previous studies showing that poor growth rates and illness in calves reduce their longevity and profitability as adult cows [30] [31]. It is therefore crucial that sufficient feed and a suitable housing environment are provided to ensure that calves get off to a good start.

The large difference in cost of weaning between organic and conventional farms was influenced to a large extent by the cost of feeding in the different systems. Organic milk powder is on average $£ 500$ per tonne more expensive than conventional milk powders while the cost of feeding whole milk is more expensive due to organic milk carrying a premium farmgate price. Also organic farms in the UK are required to feed milk to calves for a minimum of 12 weeks, which can be twice as long as on a conventional farm. Spring calved heifers had the lowest cost of rearing during the pre-weaning period. This is likely due in part to their having the earliest mean age at weaning (59 days) compared to the other three calving systems (62 - 63 days) but also due to spring born calves having the lowest cost of veterinary medicines at half the cost for autumn born calves and between 3 and 4 times lower than all year round and multi block calving herds respectively. Season of birth has been shown to affect calf mortality and disease incidence with calves born during winter more likely to die than calves born during summer and autumn with cause of death due to pneumonia and enteritis [32] [33].

\section{Conclusion}

In conclusion, the cost of rearing dairy heifers to weaning age varied considerably and was influenced largely by the farm's feeding programme, in particular the volume and duration of milk feeding. The farm policy on hygiene and comfort in terms of calf bedding and housing affected total costs to a lesser extent, although the hidden costs that this had on calves in terms of thermoregulation and disease burden were difficult to quantify. Running an organic enterprise cost significantly more during the pre-weaned period than on a conventional farm. The season of calving was another major consideration with lowest costs attributed to spring calving herds.

\section{Acknowledgements}

The authors thank all the dairy farmers who participated in the study. The work was co-funded by DairyCo and the BBSRC.

\section{References}

[1] Brickell, J.S., McGowan, M.M., Pfeiffer, D.U. and Wathes, D.C. (2009) Mortality in Holstein-Friesian Calves and Replacement Heifers in Relation to Body Weight and IGF-I Concentration, on 19 Farms in England. Animal, 3, 11751182. http://dx.doi.org/10.1017/S175173110900456X

[2] Henderson, L., Miglior, F., Sewalem, A., Kelton, D., Robinson, A. and Leslie, K.E. (2011) Estimation of Genetic Parameters for Measures of Calf Survival in a Population of Holstein Heifer Calves from a Heifer-Raising Facility in New York State. Journal of Dairy Science, 94, 461-470.

[3] Heinrichs, A.J., Heinrichs, B.S., Harel, O., Rogers, G.W. and Place, N.T. (2005) A Prospective Study of Calf Factors Affecting Age, Body Size, and Body Condition Score at First Calving of Holstein Dairy Heifers. Journal of Dairy Science, 88, 2828-2835. http://dx.doi.org/10.3168/jds.S0022-0302(05)72963-5

[4] Bach, A., Valls, N., Solans, A. and Torrent, T. (2008) Associations between Nondietary Factors and Dairy Herd Performance. Journal of Dairy Science, 91, 3259-3267. http://dx.doi.org/10.3168/jds.2008-1030

[5] Cooke, J.S., Cheng, Z., Bourne, N.E. and Wathes, D.C. (2013) Association between Growth Rates, Age at First Calving and Subsequent Fertility, Milk Production and Survival in Holstein-Friesian Heifers. Open Journal of Animal Sciences, 3, 1-12. http://dx.doi.org/10.4236/ojas.2013.31001 
[6] Mourits, M.C.M., Huirne, R.B.M., Dijkhuizen, A.A., Kristensen, A.R. and Galligan, D.T. (1999) Economic Optimization of Dairy Heifer Management Decisions. Agricultural Systems, 61, 17-31. http://dx.doi.org/10.1016/S0308-521X(99)00029-3

[7] Wathes, D.C., Pollott, G.E., Johnson, K.F., Richardson, H. and Cooke, J.S. (2014) Heifer Fertility and Carry over Consequences for Life Time Production in Dairy and Beef Cattle. Animal, 8, 91-104. http://dx.doi.org/10.1017/S1751731114000755

[8] Khan, M.A., Lee, H.J., Lee, W.S., Kim, H.S., Kim, S.B., Ki, K.S., Ha, J.K., Lee, H.G. and Choi, Y.J. (2007) Pre- and Post-weaning Performance of Holstein Female Calves Fed Milk through Step-Down and Conventional Methods. Journal of Dairy Science, 90, 876-885. http://dx.doi.org/10.3168/jds.S0022-0302(07)71571-0

[9] Davis Rincker, L.E., VandeHaar, M.J., Wolf, C.A., Liesman, J.S., Chapin, L.T. and Weber Nielsen, M.S. (2011) Effect of Intensified Feeding of Heifer Calves on Growth, Pubertal Age, Calving Age, Milk Yield, and Economics. Journal of Dairy Science, 94, 3554-3567. http://dx.doi.org/10.3168/jds.2010-3923

[10] Heinrichs, A.J. and Heinrichs, B.S. (2011) A Prospective Study of Calf Factors Affecting First-Lactation and Lifetime Milk Production and Age of Cows When Removed from the Herd. Journal of Dairy Science, 94, 336-341. http://dx.doi.org/10.3168/jds.2010-3170

[11] Svensson, C., Hultgreen, J. and Oltenacu, P.A. (2006) Morbidity in 3 - 7 Month Old Dairy Calves in South-Western Sweden, and Risk Factors for Diarrhoea and Respiratory Disease. Preventive Veterinary Medicine, 74, 162-179. http://dx.doi.org/10.1016/j.prevetmed.2005.11.008

[12] Hultgren, J., Svensson, C., Maizon, D.O. and Oltenacu, P.A. (2008) Rearing Conditions, Morbidity and Breeding Performance in Dairy Heifers in Southwest Sweden. Preventive Veterinary Medicine, 87, 244-260. http://dx.doi.org/10.1016/j.prevetmed.2008.04.003

[13] Donovan, G.A., Dohoo, I.R., Montgomery, D.M. and Bennett, F.L. (1998) Calf and Disease Factors Affecting Growth in Female Holstein Calves in Florida, USA. Preventive Veterinary Medicine, 33, 1-10. http://dx.doi.org/10.1016/S0167-5877(97)00059-7

[14] Waltner-Toews, D., Martin, S.W. and Meek, A.H. (1986) The Effect of Early Calfhood Health Status on Survivorship and Age at First Calving. Canadian Journal of Veterinary Research, 50, 314-317.

[15] Vasseur, E., Rushen, J., de Passillé, A.M., Lefebvre, D. and Pellerin, D. (2010) An Advisory Tool to Improve Management Practices Affecting Calf and Heifer Welfare on Dairy Farms. Journal of Dairy Science, 93, 4414-4426. http://dx.doi.org/10.3168/jds.2009-2586

[16] Agricultural Wages Board (2012) The Agricultural Wages (England and Wales) Order 2012. https://www.gov.uk/government/uploads/system/uploads/attachment_data/file/69593/awo12.pdf

[17] Davis, C.L. and Drackley, J.K. (1998) The Development, Nutrition, and Management of the Young Calf. University Press, Ames.

[18] Jasper, J. and Weary, D.M. (2002) Effects of Ad Libitum Milk Intake on Dairy Calves. Journal of Dairy Science, 85, 3054-3058. http://dx.doi.org/10.3168/jds.S0022-0302(02)74391-9

[19] DairyCo. (2012) PD+ Section 10-Managing Heifer Rearing. http://www.dairyco.org.uk/resources-library/technical-information/fertility/pdplus-section-10-managing-heifer-rearing/ \#.UxTkmON_slI

[20] DairyCo. (2009) Energy Efficiency on Farm — A Practical Guide. http://www.dairyco.org.uk/resources-library/technical-information/business-management/energy-efficiency-on-farm/

[21] Agro Business Consultants Ltd. (2013) The Agricultural Budgeting and Costing Book. Melton Mowbray.

[22] Barnard, C.S. and Nix, J.S. (1979) Farm Planning and Control. Cambridge University Press, Cambridge.

[23] Department of Agriculture and Rural Development North Ireland (DARDNI) (2014) Farm Business Data 2014. http://www.dardni.gov.uk/farm_business_data_2014.pdf

[24] Promar International (2011) What Are Heifer Replacements Really Costing You? http://www.milkminder.co.uk/news/Heifer\%20costs.PDF

[25] Karzes, J. (2005) Dairy Replacement Programs: Cost and Analysis. Proceedings NRAES Dairy Calves and Heifers: Integrating Biology and Management, Syracuse, 2005, 10-23.

[26] Mohd Nor, N., Steeneveld, W., Mourits, M.C.M. and Hogeveen, H. (2012) Estimating the Costs of Rearing Young Dairy Cattle in the Netherlands Using a Simulation Model that Accounts for Uncertainty Related to Diseases. Preventive Veterinary Medicine, 106, 214-224. http://dx.doi.org/10.1016/j.prevetmed.2012.03.004

[27] Heinrichs, A.J., Jones, C.M., Gray, S.M., Heinrichs, P.A., Cornelisse, S.A. and Goodling, R.C. (2013) Identifying Efficient Dairy Heifer Producers Using Production Costs and Data Envelopment Analysis. Journal of Dairy Science, 96, 7355-7362. http://dx.doi.org/10.3168/jds.2012-6488 
[28] Hill, T.M., Bateman II, H.G., Aldrich, J.M. and Schlotterbeck, R.L. (2011) Comparisons of Housing, Bedding, and Cooling Options for Dairy Calves. Journal of Dairy Science, 94, 2138-2146. http://dx.doi.org/10.3168/jds.2010-3841

[29] Gabler, M.T., Tozer, P.R. and Heinrichs, A.J. (2000) Development of a Cost Analysis Spreadsheet for Calculating the Costs to Raise a Replacement Dairy Heifer. Journal of Dairy Science, 83, 1104-1109. http://dx.doi.org/10.3168/jds.S0022-0302(00)74975-7

[30] Brickell, J.S., Bourne, N., McGowan, M.M. and Wathes, D.C. (2009) Effect of Growth and Development during the Rearing Period on the Subsequent Fertility of Nulliparous Holstein-Friesian Heifers. Theriogenology, 72, 408-416. http://dx.doi.org/10.1016/j.theriogenology.2009.03.015

[31] Brickell, J.S. and Wathes, D.C. (2011) A Descriptive Study of the Survival of Holstein-Friesian Heifers through to Third Calving on English Dairy Farms. Journal of Dairy Science, 94, 1831-1838. http://dx.doi.org/10.3168/jds.2010-3710

[32] Gulliksen, S.M., Lie, K.I., Løken, T. and Østerås, O. (2009) Calf Mortality in Norwegian Dairy Herds. Journal of Dairy Science, 92, 2782-2795. http://dx.doi.org/10.3168/jds.2008-1807

[33] Johanson, J.M. and Berger, P.J. (2003) Birth Weight as a Predictor of Calving Ease and Perinatal Mortality in Holstein Cattle. Journal of Dairy Science, 86, 3745-3755. http://dx.doi.org/10.3168/jds.S0022-0302(03)73981-2 